\title{
CXLII. DETERMINATION OF IODINE IN BLOOD.
}

\author{
BY HAROLD JAMES PERKIN. \\ From the Department of Medical Research, Banting Institute, \\ University of Toronto.
}

(Received May 30th, 1933.)

THE purpose of this investigation was to establish a reliable and accurate method for the quantitative determination of small amounts of iodine. The following procedure has been elaborated.

A weighed amount of normal whole blood, up to $10 \mathrm{cc} .$, is placed in a nickel crucible of $50 \mathrm{cc}$. capacity, together with $2 \mathrm{~g}$. of potassium carbonate (Merck's Blue Label). The crucible is placed directly in an electric muffle furnace heating to $500^{\circ}$ in 30 minutes. Then the oven is adjusted to maintain this temperature, as indicated by a thermometer. Heating is continued for 4 hours. The charred mass is broken up and finely ground with a spatula, care being taken to retain every particle in the crucible. Depending on the amount of ash present, water is added to form a pasty mass such as will fall away from the side of the crucible. This paste is extracted with $95 \%$ alcohol 4 times, using 7 cc. each time. The extracts are passed through a filter paper (Whatman No. 5, $7 \mathrm{~cm}$.), the filtrate being caught in a round-bottomed pyrex dish of $30 \mathrm{cc}$. capacity. This alcoholic solution is evaporated to dryness on an electric hot plate layered with asbestos, boiling being carefully avoided. The dry residue is now taken up with $1 \mathrm{cc}$. of water and transferred to a tube of diameter $1 \mathrm{~cm}$. and length $2.5 \mathrm{~cm}$., in which are placed 10 or 12 small capillary tubes sealed at the upper end. The solution is made slightly acid with $0.1 \mathrm{~N}_{2} \mathrm{SO}_{4}$, a micro-drop of a saturated aqueous solution of methyl orange serving as an indicator. In order to oxidise the potassium iodide to iodate, 4 drops of a freshly prepared aqueous solution of bromine are added. The tubes are placed directly in contact with an electric hot plate. The capillary tubes ensure regular and steady boiling. The solution is boiled for 1 minute. 20 seconds after the initiation of boiling, the yellow colour of the bromine disappears. The tubes are immediately placed on ice. A small drop ( $0.02 \mathrm{cc}$.) of a potassium iodide solution containing approximately $100 \gamma$ of iodine is added. Iodine is liberated to 6 times the amount originally present. One drop of starch solution is added and the solution titrated to colourless using $0.01 \mathrm{~N}$ sodium thiosulphate in a micro-burette. (150 divisions of thiosulphate from the micro-burette used were equivalent to $1.08 \gamma$ of original iodine.)

It has been found, using the above method, that blood of rabbits under standard laboratory conditions contains $8.00 \gamma$ of iodine per $100 \mathrm{~g}$. Normal male human beings for this region showed blood-iodine contents of 6.50 to $9.00 \gamma$ per $100 \mathrm{~g}$.

The method is also applicable to the determination of the iodine content of urine and other body fluids. 
The lack of unanimity of opinion on this subject indicates that a satisfactory method had not yet been established. Two factors are possibly involved: the limitations of the methods themselves, and the inability of one investigator to interpret accurately and repeat the prescribed technical procedure of another. However, it is hoped that this simplified technique, as detailed above, will permit repetition with satisfactory results.

\section{Discussion.}

The ashing process may be employed either with an acid or alkaline medium. Using acidification, the ashing must be carried out in a closed system, which makes it very complicated, and for this reason acidification was not used in this investigation. Pfeiffer [1928] employed the acidification method, which was later modified by Glimm and Isenbruch [1929] and has more recently been used by Baumann and Metzger [1932].

Von Fellenberg [1923] used the alkaline method, but noted that ashing carried out under certain conditions resulted in a loss of iodine. The work of Höjer [1928] and of Jochmann [1928] is of considerable importance in that they demonstrated the necessity of carrying out the ashing at a constant temperature. Scheffer [1930] also showed that the volatility of iodine in the presence of organic material was increased in the absence of alkali. Obviously, the ashing temperature should not exceed the melting-point of potassium iodide, which for the pure substance is $680^{\circ}$. The above observations indicated that in ashing, two conditions should be fulfilled: $(a)$ a constant ashing temperature not above $500^{\circ} ;(b)$ the presence of excess alkali. As suggested by Scheffer [1930], reported by Allot, Dauphinee and Hurtley [1932] and confirmed in this study, organic matter containing iodine could be burnt in the presence of potassium carbonate without loss of iodine. For the first condition, an electric muffle furnace fitted with an adjustable rheostat was found satisfactory. Potassium carbonate was used as alkali.

Roman [1929] reported that the complete ashing of the blood was not necessary for the complete extraction of iodine. The iodine in the carbon-containing ash is capable of extraction with alcohol, but it needs to be emphasised that water must be present for the complete extraction of iodine. Scheffer [1930] and Turner [1930] illustrated this experimentally. In the present investigation, when absolute alcohol alone was used in extraction, a recovery of only $60 \%$ was found, whereas with added water complete extraction was obtained. In evaporating the alcohol, boiling should be avoided, a point not universally recognised.

The final estimation of iodine may be carried out colorimetrically or titrimetrically. For the colorimetric method the iodine is changed into the elemental form and then mobilised in chloroform or carbon tetrachloride. Realising the limitations of the colorimetric procedure [Turner, 1930], it was considered desirable to develop the titrimetric method.

Chlorine [Veil and Sturm, 1925], potassium permanganate [Roman, 1929] and bromine [Leitch and Henderson, 1926] have been used as agents to oxidise the iodide to iodate. Any oxidising agent would be suitable, provided that the excess could be neutralised or driven off and thus not interfere with the later stages of the titrimetric procedure. A saturated aqueous solution of bromine was found most suitable since the excess could readily be removed by boiling. As recognised by Reith [1929], the bromine water, to be efficient, must be prepared freshly each day. The time of boiling must be carefully regulated, since excessive 
boiling leads to a loss of iodine. As reported by Allot, Dauphinee and Hurtley [1932], boiling for longer than 2 minutes involves a loss of iodine.

It was found that a definite ratio must exist between the iodine of the iodate and the potassium iodide added in order to obtain a true starch blue colour. This ratio was found to be approximately $1: 100$. Variations from this ratio produced a purple-red coloured solution, the colour of which did not always disappear at the true end-point. This phenomenon has been described at some length by Reith [1929] and Allot, Dauphinee and Hurtley [1932]. On this basis, a knowledge of the approximate amount of iodine present in an unknown material assists in its accurate estimation.

The sharpness of the end-point increases with a corresponding decrease in the volume of the solution and with an increase in concentration of the thiosulphate used in titration. To limit the error involved in the first instance, the final volume was arranged not to exceed $1.5 \mathrm{cc}$. To limit the second factor a micro-burette was made from a $300^{\circ}$ thermometer, the bore of which was uniform throughout its length. The upper end of this burette was bent to form an inverted $U$, the end of which could be immersed in the solution to be titrated. The level of the thiosulphate in the burette was controlled by a mercury sac containing a screw on the lower end of the burette. $0.01 \mathrm{~N}$ sodium thiosulphate was used and prepared freshly each day from a $0 \cdot 1 \mathrm{~N}$ stock solution. Each 10 divisions of the burette delivered a volume of $0.321 \mathrm{~mm}^{3}$ A definite blue colour could be detected and could be accurately discharged with thiosulphate on $0.2 \gamma$ of iodine. One drop of a $1 \%$ starch in saturated sodium chloride solution served as an indicator. By these means the titration error was reduced to a minimum. Air, bubbling from a fine tip, was used for stirring, too much bubbling being avoided, since it was found to drive off iodine. The point at which the blue colour did not return in 15 minutes was considered to be the true end-point.

. Blank determinations using $10 \mathrm{cc}$. of water in place of blood showed consistent values of $0 \cdot 2 \gamma$ iodine. $1 \gamma$ of iodine added, as inorganic or organic iodine, could be recovered to $96 \%$. When similar amounts were added to whole blood of a known iodine content, they could be recovered to $94 \%$. Therefore, the error of the method was less than $10 \%$.

\section{SUMMARY.}

A modified technique has been devised for the quantitative determination of iodine, in quantities such as are present in blood.

This method has an error of less than $10 \%$.

Contamination must be carefully avoided in micro-estimations of iodine.

Strict adherence to an established technique is essential. The results secured, if not strictly quantitative, are at least comparable.

I wish to take this opportunity of expressing my gratitude to Dr E. J. King and Dr F. G. Banting for their constructive criticism and helpful suggestions during the course of this investigation. 


\section{REFERENCES.}

Allot, Dauphinee and Hurtley (1932). Biochem. J. 26, 1665. Baumann and Metzger (1932). J. Biol. Chem. 98, 405.

von Fellenberg (1923). Biochem. Z. 139, 371.

Glimm and Isenbruch (1929). Biochem. Z. 207, 368.

Höjer (1928). Biochem. Z. 205, 273.

Jochmann (1928). Biochem. Z. 194, 454.

Leitch and Henderson (1926). Biochem. J. 20, 1003.

Pfeiffer (1928). Biochem. Z. 195, 128.

Reith (1929). Biochem. Z. 216, 249.

Roman (1929). Biochem. Z. 207, 416.

Scheffer (1930). Biochem. Z. 228, 426.

Turner (1930). J. Biol. Chem. 88, 497.

Veil and Sturm (1925). Deutsch. Arch. klin. Med.147, 166. 